Original Research Article

\title{
Drug utilization study of antihypertensive drugs and prevalence of blood pressure control in adult hypertensive patients based on JNC VIII guidelines in a tertiary care hospital: a cross sectional study
}

\author{
Saumya Ramadas ${ }^{1 *}$, M. B. Sujatha ${ }^{2}$, M. A. Andrews ${ }^{3}$, Sanalkumar K. B. ${ }^{4}$
}

\begin{abstract}
${ }^{1}$ Department of Pharmacology, Govt. Medical College, Palakkad, Kerala, India

${ }^{2}$ Department of Pharmacology, Govt. Medical College Manjeri, Kerala, India

${ }^{3}$ Principal \& Head of Department of Medicine, Govt. Medical College Thrissur, Kerala, India ${ }^{4}$ Department of Pharmacology, Govt. Medical College Thrissur, Kerala, India
\end{abstract}

Received: 26 November 2018 Accepted: 28 December 2018

\section{*Correspondence to: \\ Dr. Saumya Ramadas, Email: Saumya.ramdas@ gmail.com}

Copyright: () the author(s), publisher and licensee Medip Academy. This is an open-access article distributed under the terms of the Creative Commons Attribution Non-Commercial License, which permits unrestricted non-commercial use, distribution, and reproduction in any medium, provided the original work is properly cited.

\begin{abstract}
Background: Hypertension is a major independent risk factor for coronary artery disease, congestive heart failure, stroke, chronic kidney disease and peripheral vascular diseases if left untreated. Drug utilization study of antihypertensive drugs and the study on prevalence of blood pressure control would help in reducing the burden of the disease and health expenditure.

Methods: The study was conducted in the Outpatient Department of Medicine in Government Medical College, Thrissur. Patients aged 18yrs or above diagnosed with hypertension, on antihypertensive drugs were enrolled in the study. Patients suffering from secondary hypertension and acutely ill were excluded. Patients were enrolled after taking an informed consent. Demographic data, present treatment for hypertension, associated co- morbid conditions if any, and treatment of the same were recorded. BP was recorded, and cost of treatment was calculated using CIMS.

Results: A total of 250 patients were included in the study. Mono therapy was used in $64.8 \%$ patients and combination therapy in $35.2 \%$. Overall drug utilization pattern showed that CCBs $(42.8 \%)$ were most commonly prescribed, followed by ACEIs (32.4\%) and ARBs (29.2\%). Most commonly prescribed combination therapy was ACE I + BB (29.3\%), followed by ARB + CCB (21.3\%). Mean cost of antihypertensive drug therapy was 3057.8 Rs / yr. Recommended target BP was achieved in $49.6 \%$ of patients.

Conclusions: The prescription pattern of antihypertensive drug was in accordance to the JNC-VIII guidelines. The blood pressure target was achieved only in less than $50 \%$ of patients.
\end{abstract}

Keywords: Antihypertensive Drugs, Hypertension, JNC - 8, Target BP

\section{INTRODUCTION}

Hypertension is an asymptomatic disorder and usually comes into picture only when the patient presents with some end organ damage, hence it is referred to as a silent killer. ${ }^{1}$ It is the $3^{\text {rd }}$ killer disease. ${ }^{2}$ World Health Statistics 2012 states that, every 1 in 3 adults has a high BP. ${ }^{3}$ In 2000 it was estimated that 1 billion i.e. nearly a quarter of the world's population is suffering from hypertension. Prevalence of hypertension was estimated to be $40 \%$ in adults more than 25years in 2008. It is estimated to increase to 1.56 billion by $2025 .^{4}$

India is the second largest country in the world on the basis of its population, so a major chunk of any disease statistics can easily be attributed to her. Hypertension is the most common chronic health disorder in India. ${ }^{4}$ According to the global status report 2010 by WHO; prevalence of hypertension is $32.5 \%$. Males have a slightly higher prevalence in comparison to females. Recent studies show 
that for every known person with hypertension, there are two people with either undiagnosed hypertension or prehypertension. ${ }^{5}$ Three serial epidemiological studies in the years 1994, 2001 and 2003 showed a prevalence of hypertension as $30 \%, 36 \%$ and $51 \%$ respectively in males while in females it was $34 \%, 38 \%$ and $51 \%$ respectively. ${ }^{6}$

State of Kerala has high life expectancy, which is comparable to European standards. Since the prevalence of hypertension increases in elderly, Kerala has a large chunk of hypertensive patients. MOHFW reports a prevalence of $69 \%$ and $55 \%$ among urban and rural elderly population in Kerala. Another study conducted in Thiruvananthapuram district of Kerala, which showed a prevalence of $47 \%$ which is much higher than national prevalence. Another study showed an incidence of $38 \%$ in Kumarakom, a rural area in Kottayam district of Kerala. ${ }^{3,6}$

It is worthy to note that hypertension incurs a great deal of financial burden to the families of the affected. The annual income loss due to NCDs among working adults in India was $₹_{251}$ billion (about US\$ 50 billion) and that due to hypertension alone amounted to $₹_{43}$ billion according to 2004 reports. $^{7}$

Reducing blood pressure with life style modification and antihypertensive drugs can effectively tackle the burden of this disease on our state and the nation. Evidence from several randomized controlled trials has shown that antihypertensive drugs can effectively reduce morbidity and mortality due to hypertension. ${ }^{8}$

Studying the drug utilization pattern of antihypertensive drugs and prevalence of blood pressure control with respect to the current guidelines for management of hypertension, would help to bring into light any inadequacies in management of hypertension and thus help to impede the mortality and morbidity. There are very few studies done on pattern of use of antihypertensive drugs in South India, especially in Kerala in view of the change in recommendations by the latest JNC 8 guidelines.

\section{METHODS}

The design of this study was cross sectional study, Study setting at Outpatient Department, Medicine, Govt. Medical College, Thrissur.

Hypertensive patients, attending the Medicine OPD during the study period, who have been on treatment with antihypertensive drugs for a minimum period of 1 month, were enrolled in the study. The study period was 6months, December 2014 to June 2015.

\section{Inclusion criteria}

- Essential hypertensive patients of either gender
- More than 18years attending the Medicine OPD on treatment with at least one antihypertensive drug, for a minimum period of 1 month.

\section{Exclusion criteria}

- Acutely ill

- Mentally retarded

- Pregnant and lactating women

\section{Sample size}

The sample size was derived using the Kish Leslie equation for descriptive studies, as follows

$\mathrm{N}=\frac{Z^{2} p q}{d^{2}}$, where $\mathrm{Z}=1.96$, which corresponds to the $95 \%$ confidence interval;

$\mathrm{p}=\mathrm{p}$ is the prevalence from a previous study, taken as $29.5^{9}$

$q=100-P ;$ and

$d=$ calculated as $20 \%$ of $p$ i.e. the allowable error

Sample size was 250

Convenience sampling was used.

\section{Study procedure}

The study was initiated after getting approval from the Institutional Ethics Committee, Government Medical College, Thrissur. The eligible hypertensive patients, attending the Medicine Outpatient Department, Government Medical College, Thrissur, were enrolled into the study after getting an informed consent.

Data were collected in predesigned data collection forms. Demographic data of the patients were collected. Height and weight of the patient was recorded to calculate the BMI. Duration of the hypertension and antihypertensive treatment were recorded. Details of co morbidities and drugs prescribed for the same were also noted.

Details of the present treatment for hypertension; the name and class of antihypertensive drug, dose and frequency of administration were recorded. Whether the drugs were prescribed by generic and brand name was also noted. The cost of antihypertensive drug therapy was calculated as a function of the dose prescribed and the price in current index of medical specialties (CIMS 2016).

BP was recorded with the patient seated and relaxed for 5 minutes prior to the reading. Patient was seated with legs uncrossed, arms and back supported. BP was measured using a mercury sphygmomanometer. Two readings were taken, 1minute apart and the average of the two was recorded. If the difference between the two readings was 
more than $5 \mathrm{~mm}$ of $\mathrm{Hg}$, additional readings were taken. ${ }^{10}$ Methodology is represented pictorially in Figure 1.

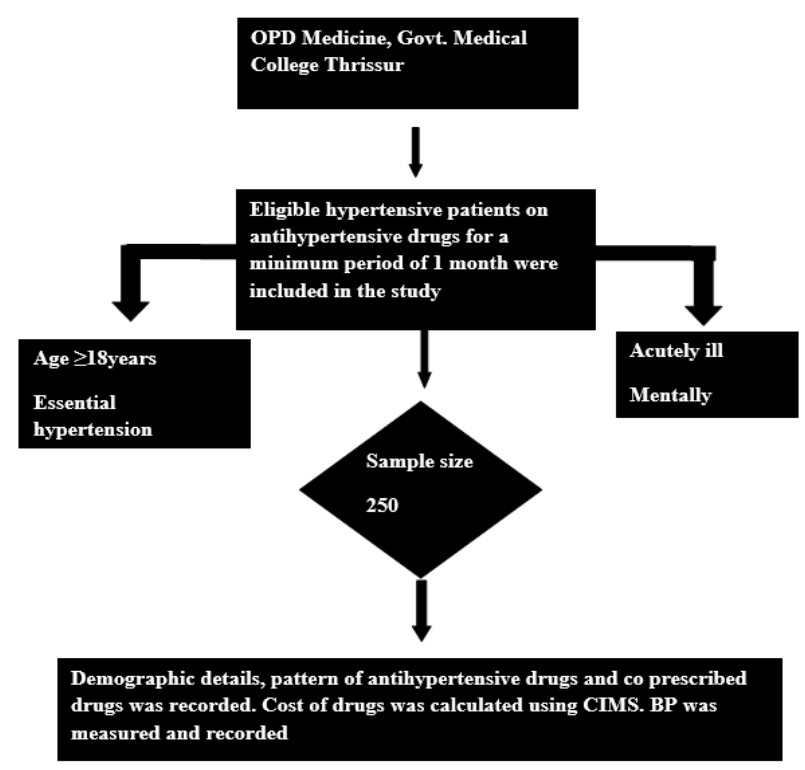

Figure 1: Overview of study procedure.

\section{Ethical concern}

The present study did not include any intervention or investigations on the patient or any other human or animal. Ethical clearance was obtained from Institutional Ethics Committee, Govt. Medical College Thrissur and clearance from patient support group was obtained.

\section{RESULTS}

\section{Demographic characteristics}

As shown in Table 1, among the 250 subjects, there were 126 males $(50.4 \%)$ and $124(49.6 \%)$ females. Maximum number of patients belonged to the age group 60 - 69years. The mean age of the study population was $62.64 \pm 10.96 \mathrm{yrs}$. $80 \%$ of our study subjects were dwelling in the rural areas of Thrissur and Palakkad districts of Kerala. Most of them belonged to the low socioeconomic group. $74.4 \%$ of the study subjects were unemployed.79.6\% had basic schooling or higher education. $27.6 \%$ were overweight and $2.8 \%$ were obese based on BMI.

\section{Distribution of co-morbidities}

As shown in Figure 2, most common co morbidity associated with hypertension in this study was ischemic heart disease $37.6 \%$ followed by diabetes $34.4 \%$.

\section{Distribution of study population based on the Blood pressure}

$31.2 \%$ of patients had a BP between $140 / 90$ and $160 / 100 \mathrm{~mm}$ of $\mathrm{Hg}$ and $27.2 \%$ of population had a BP more than $160 / 100 \mathrm{~mm}$ of $\mathrm{Hg}$, as shown in Table 2. Mean SBP and DBP of the study population was 141.3 \pm 21.2 and $84.5 \pm 12.3$ respectively. Mean duration of hypertension was found to be 6.24years in males and 7.09years in the females.

Table 1: Demographic characteristics of hypertensive patients.

\begin{tabular}{|c|c|c|c|}
\hline \multicolumn{2}{|c|}{ Demographic character } & Number & Percentage \\
\hline \multirow{2}{*}{ Gender } & Male & 126 & 50.4 \\
\hline & Female & 124 & 49.6 \\
\hline \multirow{5}{*}{ Age group } & $<29$ & 2 & 0.8 \\
\hline & $30-39$ & 2 & 0.8 \\
\hline & $40-59$ & 77 & 30.8 \\
\hline & $60-79$ & 100 & 40 \\
\hline & $\geq 80$ & 69 & 27.6 \\
\hline \multirow{2}{*}{ Domicile } & Rural & 216 & 86.4 \\
\hline & Urban & 31 & 13.6 \\
\hline \multirow{2}{*}{$\begin{array}{l}\text { Economic } \\
\text { status }\end{array}$} & BPL & 202 & 80.8 \\
\hline & APL & 48 & 19.2 \\
\hline \multirow{3}{*}{$\begin{array}{l}\text { Educational } \\
\text { status }\end{array}$} & Schooling & 184 & 73.6 \\
\hline & $\begin{array}{l}\text { Higher } \\
\text { education }\end{array}$ & 15 & 6 \\
\hline & Illiterate & 52 & 20.4 \\
\hline \multirow{4}{*}{ Marital status } & Married & 170 & 68 \\
\hline & Unmarried & 14 & 3.6 \\
\hline & $\begin{array}{l}\text { Widow/ } \\
\text { Widower }\end{array}$ & 62 & 24.8 \\
\hline & Divorced & 4 & 3.6 \\
\hline \multirow{4}{*}{ BMI } & Underweight & 24 & 9.6 \\
\hline & Normal & 150 & 60 \\
\hline & Over weight & 69 & 27.6 \\
\hline & Obese & 7 & 2.8 \\
\hline
\end{tabular}

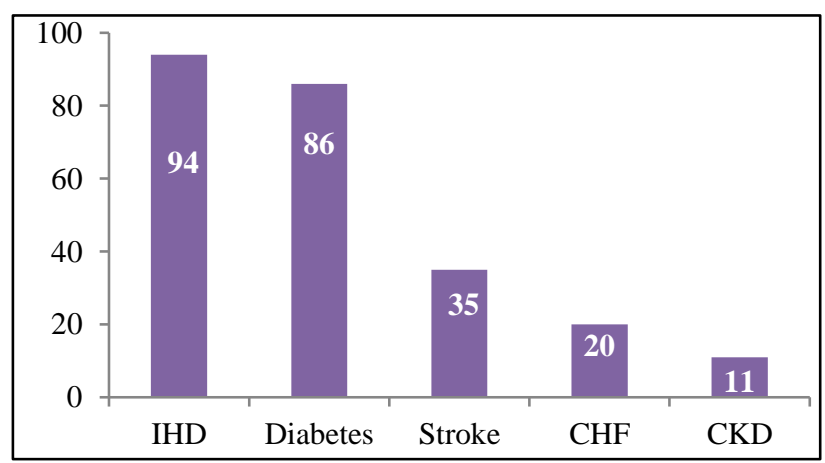

Figure 2: Distribution of co-morbidities.

Table 2: Distribution of hypertensives based on their $B P$ recorded at the time of visit.

\begin{tabular}{|lll|}
\hline BP $(\mathbf{m m}$ of $\mathbf{H g})$ & Number $(\mathbf{n = 2 5 0})$ & Percentage \\
\hline$<140 / 90$ & 104 & 41.6 \\
\hline$<160 / 100$ & 78 & 31.2 \\
\hline$\geq 160 / 100$ & 68 & 27.2 \\
\hline
\end{tabular}


Table 3: Pattern of use of antihypertensive drugs.

\begin{tabular}{|c|c|c|c|c|c|c|}
\hline \multicolumn{7}{|c|}{ Overall drug utilization pattern in patients on treatment for hypertension $(\mathrm{n}=\mathbf{2 5 0})$} \\
\hline Drugs & CCB & ACE I & $\mathrm{ARB}$ & BB & Diuretic (Thiazide) & Central Sympatholytic \\
\hline No: & 107 & 81 & 73 & 53 & 15 & 20 \\
\hline$\%$ & 42.8 & 32.4 & 29.2 & 21.2 & 6 & 8 \\
\hline \multicolumn{7}{|c|}{ Drug utilization pattern in patients on single drug therapy for hypertension $(n=162)$} \\
\hline Drugs & CCB & ACE I & $\mathrm{ARB}$ & BB & Diuretic (Thiazide) & Central Sympatholytic \\
\hline No: & 59 & 44 & 43 & 5 & 5 & 6 \\
\hline$\%$ & 36.4 & 27.1 & 26.5 & 3.1 & 3.1 & 3.7 \\
\hline \multicolumn{7}{|c|}{ Drug utilization pattern in patients on dual drug therapy for hypertension $(n=75)$} \\
\hline ACE I & & & & & 22 & 29.3 \\
\hline $\mathrm{ARB}+$ & & & & & 16 & 21.3 \\
\hline $\mathrm{ARB}+$ & & & & & 8 & 10.7 \\
\hline $\mathrm{CCB}+$ & & & & & 8 & 10.7 \\
\hline $\mathrm{ACE}+$ & & & & & 5 & 6.7 \\
\hline $\mathrm{CCB}+$ & 1 Symp & tics & & & 5 & 6.7 \\
\hline $\mathrm{ARB}+$ & ic (This & & & & 4 & 5.3 \\
\hline ACE I & al Sym & lytic & & & 2 & 2.7 \\
\hline $\mathrm{ARB}+$ & 1 Symp & & & & 2 & 2.7 \\
\hline $\mathrm{CCB}+$ & & & & & 2 & 2.7 \\
\hline $\mathrm{BB}+\mathrm{C}$ & Sympat & & & & 1 & 1.3 \\
\hline \multicolumn{7}{|c|}{ Drug utilization pattern in patients receiving 3 or more drugs for hypertension $(n=13)$} \\
\hline $\mathrm{ACE}+$ & - BB & & & & 5 & 38.4 \\
\hline $\mathrm{ACE}+$ & $\mathrm{ic}+\mathrm{Ce}$ & ympathe & & & 1 & 7.6 \\
\hline $\mathrm{ARB}+$ & - BB & & & & 1 & 7.6 \\
\hline $\mathrm{ARB}+$ & - Diure & liazide) & & & 1 & 7.6 \\
\hline $\mathrm{ARB}+$ & ic (Thi & + Centra & npatho & & 1 & 7.6 \\
\hline $\mathrm{CCB}+$ & Central & atholytic & & & 1 & 7.6 \\
\hline $\mathrm{ARB}+$ & - $\mathrm{BB}+$ & & & & 1 & 7.6 \\
\hline $\mathrm{ACE}+$ & Diuretic & ntral Syn & olytic & & 1 & 7.6 \\
\hline
\end{tabular}

Table 4: Pattern of antihypertensive drugs prescribed in hypertensive patients with co morbidities.

\begin{tabular}{|llllll|}
\hline Disease & ACE I & ARB & CCB & BB & Diuretics \\
\hline IHD $(\mathrm{n}=94)$ & $45(47.9)$ & $30(31.9)$ & $25(26.6)$ & $42(44.6)$ & $5(5.3)$ \\
\hline Diabetes $(\mathrm{n}=86)$ & $28(32.6)$ & $14(16.3)$ & $17(19.8)$ & $14(16.7)$ & $7(8.1)$ \\
\hline Stroke $(\mathrm{n}=35)$ & $13(37.1)$ & $4(11.4)$ & $20(57.1)$ & $4(11.4)$ & $2(5.8)$ \\
\hline CHF $(\mathrm{n}=20)$ & $8(40)$ & $7(35)$ & $4(20)$ & $1(5)$ & $8(40)$ \\
\hline CKD $(11)$ & $1(9.1)$ & $2(18.2)$ & $6(54.6)$ & 0 & $1(9.1)$ \\
\hline
\end{tabular}

Table 5: Distribution of ratio of PDD to DDD of antihypertensive drugs.

\begin{tabular}{|lllll|}
\hline Drug & Mean dose \pm SD $\left(\mathbf{P D D}^{* *}\right)$ & DDD $^{* * * *}(\mathbf{m g})$ & PDD $:$ DDD & Mean freq \pm SD \\
\hline Enalapril & $11.7 \pm 6.9$ & 10 & 1.17 & $1.6 \pm 0.4$ \\
\hline Amlodipine & $9 \pm 6.8$ & 5 & 1.8 & $1.3 \pm 0.5$ \\
\hline Atenolol & $67.3 \pm 47.9$ & 75 & 0.9 & $1.2 \pm 0.4$ \\
\hline Losartan & $99 \pm 60.9$ & 50 & 1.9 & $1.6 \pm 0.5$ \\
\hline Telmisartan & $92.3 \pm 60.8$ & 40 & 2.3 & $1.4 \pm 0.5$ \\
\hline Chlorthalidone & $6.8 \pm 1.9$ & $*$ & & $1 \pm 0$ \\
\hline
\end{tabular}

*not available, $* *$ Prescribed daily dose $* * *$ defined daily dose 
group of drug was calcium channel blocker (42.8\%), followed by RAAS blockers. Angiotensin converting enzyme inhibitor with beta blocker $(29.3 \%)$ was the most commonly prescribed combination therapy. $15.2 \%$ of the total study population was on treatment with 3 or more drugs. Most commonly prescribed combination in this category was that of Angiotensin converting enzyme inhibitor, calcium channel blocker and beta blocker. The commonest agents used to control BP in most of the co morbidities were RAAS blockers which is summarised in Table 4.

Distribution of mean doses and frequencies of antihypertensive drugs

The PDD: DDD ratio ranged from 0.9 to 2.3. The ratio was least with Atenolol and maximum with Amlodipine as shown in Table 5.
Table 6: Distribution of co prescribed drugs.

\begin{tabular}{|lll|}
\hline Drugs & Number & $\%$ \\
\hline Aspirin & 113 & 66.8 \\
\hline Atrorvastatin & 87 & 46.7 \\
\hline Metformin & 79 & 34.8 \\
\hline Clopidogrel & 54 & 31.9 \\
\hline Sulfonylureas & 48 & 28.4 \\
\hline Nitrates & 46 & 27.2 \\
\hline Vitamins & 42 & 24.8 \\
\hline Antiulcer drugs & 34 & 20.1 \\
\hline Frusemide & 22 & 13 \\
\hline Thyroxine & 21 & 12.4 \\
\hline Insulin & 20 & 11.8 \\
\hline Antiparkinsonian drugs & 14 & 8.3 \\
\hline Spironolactone & 12 & 7.1 \\
\hline Digoxin & 10 & 5.9 \\
\hline Antiepileptic drugs & 9 & 5.3 \\
\hline
\end{tabular}

Table 7: Economic outcome of antihypertensive drug therapy.

\begin{tabular}{|lllll|}
\hline \multirow{2}{*}{ Drug } & \multicolumn{2}{l}{ Cost of treatment (Rs) } & Mean & SD \\
\hline ACE I $(\mathrm{n}=80)$ & Minimum /year & Maximum/year & 1616.2 & 1392.9 \\
\hline ARB $(\mathrm{n}=74)$ & 324 & 11160 & 4053.9 & 2494.7 \\
\hline CCB $(\mathrm{n}=101)$ & 1008 & 8532 & 1949.3 & 1469.2 \\
\hline Diuretic (Thiazide) & 540 & 4464 & 780.9 & 335.5 \\
\hline BB & 216 & 1620 & 1494.7 & 1736.6 \\
\hline Central sympatholytic & 504 & 9072 & 2610 & 1643 \\
\hline Distribution of hypertensive based on cost of antihypertensive drug therapy & APL (48) & Total \\
\hline Cost (Rs) & BPL (202) & $35(72.9)$ & $201(80.4)$ \\
\hline$<5000$ & $166(82.1)$ & $10(4)$ & $36(14.4)$ \\
\hline $5001-10000$ & $26(12.9)$ & $5(10.4)$ & $11(4.4)$ \\
\hline $10001-15000$ & $6(3)$ & $3(6.7)$ & $7(2.8)$ \\
\hline$>15000$ & $4(2)$ & & \\
\hline
\end{tabular}

Table 8: Prevalence of BP control based on JNC -8 guidelines.

\begin{tabular}{|c|c|c|c|c|c|}
\hline & & \multicolumn{4}{|c|}{ Target Blood Pressure* } \\
\hline & & \multirow{2}{*}{ Achieved } & \multicolumn{3}{|c|}{ Not achieved (126 -50.4\%) } \\
\hline & & & Only DBP unachieved & Only SBP unachieved & Both unachieved \\
\hline \multicolumn{2}{|c|}{ Total $(n=250)$} & $124(49.6 \%)$ & $31(12.4 \%)$ & $29(11.6 \%)$ & $66(26.4 \%)$ \\
\hline \multicolumn{2}{|c|}{ Diabetes $(n=86)$} & $40(46.5 \%)$ & $8(9.3 \%)$ & $17(19.8 \%)$ & $21(24.4 \%)$ \\
\hline \multicolumn{2}{|c|}{ IHD $(n=94)$} & $52(55.3 \%)$ & $15(16 \%)$ & $10(10.4 \%)$ & $17(18.1 \%)$ \\
\hline \multicolumn{2}{|c|}{ Stroke $(\mathrm{n}=35)$} & $20(57.1 \%)$ & $4(11.4 \%)$ & $4(11.4 \%)$ & $7(20 \%)$ \\
\hline \multicolumn{2}{|c|}{$\mathrm{CHF}(\mathrm{n}=20)$} & $11(55 \%)$ & $1(5 \%)$ & $1(5 \%)$ & $7(35 \%)$ \\
\hline \multicolumn{2}{|c|}{$\operatorname{CKD}(\mathrm{n}=11)$} & $5(45.5 \%)$ & $1(9.1 \%)$ & $2(18.2 \%)$ & $3(27.3 \%)$ \\
\hline \multirow{2}{*}{\multicolumn{2}{|c|}{ Gender }} & \multicolumn{4}{|l|}{ Target BP } \\
\hline & & \multicolumn{2}{|l|}{ Achieved } & \multicolumn{2}{|l|}{ Not achieved } \\
\hline \multirow{2}{*}{$\mathbf{M}^{* *}$} & $<60$ yrs $(n=41)$ & $17(41.4 \%)$ & & \multicolumn{2}{|l|}{$24(58.6 \%)$} \\
\hline & $\geq 60$ yrs $(n=85)$ & $45(52.9 \%)$ & & \multicolumn{2}{|l|}{$40(47.1 \%)$} \\
\hline \multirow{2}{*}{$\mathrm{F}^{* * *}$} & $<60$ yrs $(n=40)$ & $16(40)$ & & \multicolumn{2}{|l|}{$24(60)$} \\
\hline & $\geq 60$ yrs $(n=84)$ & $39(46.4 \%)$ & & \multicolumn{2}{|l|}{$45(53.6)$} \\
\hline
\end{tabular}

$* \mathrm{BP}<140 / 90$ - general population $<60 \mathrm{yr}$, DM and CKD; BP<150/90 in general population $\geq 60 \mathrm{yrs}$; ** Males, *** Females 


\section{Pattern of co-prescribed drugs in hypertensive patients}

Most commonly co-prescribed drugs were Antiplatelets $66.8 \%$ followed by Antidiabetic agents $46.7 \%$ and Statin $34.8 \%$ as shown in Table 6.

\section{Cost analysis}

The mean cost/ year of antihypertensive drug therapy was found to be Rs. $3057.8 \pm 3107.9$. From the Table 7, authors can deduce that the cheapest class of drug was Thiazide diuretics followed by Angiotensin converting enzyme inhibitors.

\section{Prevalence of blood pressure control in study population}

As shown in Table 8, 49.6\% have achieved the target BP that is recommended by the JNC- 8 . In hypertensive patients suffering from other co morbid illnesses percentage of BP control ranged from 45.5 to 57.1. Least BP control was seen among patients suffering from a concomitant CKD.

\section{WHO Drug utilisation indicators}

Average no. of antihypertensive drugs prescribed per encounter was 1.4 whereas the average no: of total number of drugs amounted to 4.19 . Total $77.1 \%$ of antihypertensive drugs were prescribed by generic name. $9.6 \%$ of the drugs were prescribed as injection, it included mainly insulin and erythropoietin. $82.5 \%$ of antihypertensive drugs were prescribed from the NELM 2015. Results are summarised in Table 9.

Table 9: WHO drug utilisation indicators.

\begin{tabular}{|lll|}
\hline WHO drug use indicators & $\begin{array}{l}\text { Anti- } \\
\text { hypertensives }\end{array}$ & Total \\
\hline No: of drugs per encounter & 1.4 & 4.19 \\
\hline $\begin{array}{l}\text { Drugs prescribed by } \\
\text { generic name }\end{array}$ & $77.1 \%$ & $58.2 \%$ \\
\hline $\begin{array}{l}\text { Percentage of encounter } \\
\text { with injection }\end{array}$ & 0 & $9.6 \%$ \\
\hline $\begin{array}{l}\text { Percentage of drugs } \\
\text { prescribed from EDL }\end{array}$ & $82.5 \%$ & $69.7 \%$ \\
\hline
\end{tabular}

\section{DISCUSSION}

Prevalence of hypertension was $50.4 \%$ in males and $49.6 \%$ in females. This finding was in line with the prevalence data by Kale A et al, and Birader et al. ${ }^{9,11}$ Studies by Khurshid et al, Bajaj et al, and Solanki et al, in northern and western parts of India, showed a higher prevalence among females than in males. Almas et al, in Pakistan described a similar picture like the northern and western parts of India. A study by Nwaka et al, in Nigeria also described a similar picture. All these studies point out to the fact that prevalence of hypertension varies from continent to continent and also within India from region to region. ${ }^{9,11-16}$

The maximum prevalence of hypertension was seen in the age group 60-69yrs in the present study which goes hand in hand with the findings by Biradar et al, and Rajashekhar DG et al. ${ }^{11,17}$

Most prevalent co-morbid condition was IHD (37.6\%) followed by diabetes (34.4\%). India has a large subset of population with CAD and a very high prevalence of the same is seen in Kerala. ${ }^{18}$ This explains the high prevalence of IHD among the study population.

Majority of the patients $(64.8 \%)$ were on single drug therapy whereas $30 \%$ were on dual drug therapy and $5.2 \%$ were on 3 or more drugs. Studies conducted by Torvi et al, Tandon et al, and Konwar et al, also showed a preference for single therapy over combination therapy. ${ }^{19-21}$ On the other hand most of the other studies clearly showed a higher usage of multiple drug therapy over single drug therapy. A vast majority of the guidelines for hypertension now emphasise on the usage of combination therapy rather than up titration of a single drug for control of hypertension. It's been stated that mono therapy results in BP control in only $20-30 \%$ of the individuals. ${ }^{8,19}$

On observing the overall drug utilisation pattern in the present study group, it was found that CCBs were the most frequently prescribed group followed by RAAS blockers. Joseph $\mathrm{S}$ et al, in Kerala and Rachana PR et al, in Karnataka also showed that CCB was the most preferred class of drug. ${ }^{22,23}$ The trend of prescription of antihypertensives in the present study was in line with the JNC 8 guideline. Beta blockers were preferred in the present study despite losing its first line drug tag may be explained by a high prevalence of CAD. ${ }^{8}$

ACE Inhibitor and BB followed by ARB and $\mathrm{CCB}$ were the preferred combination therapy. The third most common combination was that of a BB with either an ARB or a CCB. Solanki et al, observed a similar picture with ACE I $+\mathrm{BB}$ as the most commonly prescribed combination therapy. ${ }^{14}$ Studies from Africa revealed a preference for diuretic based combination therapy. ${ }^{16}$ Among the combination therapies used in the present study, 5 of them were fixed dose combinations. Even though a combination of BB and RAAS blocker is one of the least recommended choices for BP reduction, the combination is acceptable in hypertensives with a concomitant CAD. One of the combinations seen in the present study was that of a BB with clonidine. This combination is considered irrational as this is known to cause severe bradycardia /heart block and on sudden withdrawal may precipitate rebound hypertension. ${ }^{24}$

Among the patients with IHD, majority were prescribed ACEIs and BBs. In diabetics RAAS blockers followed by CCBs were preferred. A study by Johnson et al, showed high use of RAAS blockers in management of hypertension 
associated with diabetes. ${ }^{25}$ RAAS blockers have desirable effects on urinary protein excretion and hence recommended in the management of hypertension associated with DM. CCBs were prescribed in majority of stroke patients. Studies conducted by Vurmadla et al, and Prathyusha et al, also showed a higher use of CCBs in patients with hypertension and stroke. ${ }^{26,27}$ In patients with $\mathrm{CHF}$, the most commonly prescribed group of drugs were RAAS blockers. These drugs reduce the long term mortality and morbidity associated with CHF. Baskota et al, noted an increased use of RAAS blockers and diuretics in treatment of hypertension associated with heart failure. ${ }^{28,29}$ Most of the guidelines recommend the use of RAAS blockers in the treatment of hypertension associated with CKD. ${ }^{8,24}$ Some disparity was observed between these guidelines and the present study. In 11 patients with CKD, CCBs and Clonidine were the commonly prescribed classes of drugs ahead of RAAS blockers.

Total of $49.6 \%$ had achieved the blood pressure target that was recommended by the JNC-8. Most of the patients in the study population were on single drug therapy when evidence from various meta-analysis showed that a combination therapy is required in majority of the hypertensive patients to attain the target BP. ${ }^{24,30}$ Lack of affordability of medicines may also contribute to the uncontrolled BP. Absence of awareness and lack of compliance would also have been a contributing factor. Social habits like alcoholism and smoking along with absence or inadequacy of life style interventions like regular daily exercise, weight reduction and salt restriction may also hamper the BP control.

Cost analysis of antihypertensive drug therapy revealed that the mean cost of antihypertensive therapy was Rs $3057.8 \pm 3107.9 /$ year. The least expensive class of antihypertensive drug in the present study was Diuretics (Thiazide like).

WHO drug utilisation indicators were calculated after analysing the prescriptions of the study population. WHO recommends average number of drugs per encounter as 2 3. Average number of total drugs per encounter in the present study was 4.2. The mild discrepancy from the guidelines can be explained by the fact that most of the present study population had one or more associated co morbidity along with hypertension. ${ }^{31,32}$ Average number of antihypertensive drugs per prescription was 1.4. A slightly higher value was observed by Rimoy et al, who found that the average number of antihypertensive drugs per prescription was $1.6 .{ }^{33}$ The percentage of antihypertensive drugs prescribed by their generic name was $77.1 \%$ and that of total drugs (antihypertensives + co prescribed drugs) prescribed by generic name was $58.2 \%$. This is low compared to the WHO standards which require $100 \%$ of drugs to be prescribed by their generic name. $82.5 \%$ of antihypertensive drugs were prescribed from the NELM 2015 , which is in accordance with WHO norms which require $80-100 \%$ of the drugs to be from the EDL. ${ }^{34}$ Percentage of encounters with an injection was $9.6 \%$, which is in line with the WHO recommendations of $<16-$ $20 \%$.

\section{ACKNOWLEDGEMENTS}

Authors would like to extend gratitude to all the staff from the Department of Medicine, Govt. Medical College Thrissur for helping authors in the successful completion of their research work.

\section{Funding: No funding sources Conflict of interest: None declared \\ Ethical approval: The study was approved by the Institutional Ethics Committee}

\section{REFERENCES}

1. Rosendorff C, Lackland DT, Allison M, Aronow WS, Black HR, Blumenthal RS, et al. Treatment of hypertension in patients with coronary artery disease: a scientific statement from the American Heart Association, American College of Cardiology, and American Society of Hypertension. Hypertension 2015;65(6):1372-407.

2. Meshram II, Balkrishna N, Arlappa N, Rao KM, Laxmaiah A, Brahmam GNV. Prevalence of hypertension, its correlates and awareness among adult tribal population of Kerala state, India. J Postgrad Med. 2012;58(4):255-61

3. WHO/Media centre. WHO. New data highlight increases in hypertension, diabetes incidence. World Health Organization; 2012. Available at: http://www.who.int/mediacentre/news/releases/2012/wo rld_health_statistics_20120516/en/. Accessed 10 September 2014.

4. Bhatia ML. Hypertension in India [Internet]. Coronary Artery Disease in Asian Indians. 2012. Available at: www.cadiresearch.org/topic/hypertension/hypertensionIndia. Accessed 9 October 2014.

5. World Health Organization. Global status report on noncommunicable diseases. Geneva; 2010. Available at: http://www.who.int/nmh/publications/ncd_report2010/e n/. Accessed 10 September 2014.

6. Ajay V, Gupta R, Panniyammakkal J, Chaturvedi V, Prabhakarn D, Reddy SK. National Cardiovascular Disease Database. MOHFW \& WHO. Available at: http://www.searo.who.int/india/topics/cardiovascular_di seases/NCD_Resources_National_CVD_database-

Final_Report.pdf?ua=1. Accessed 10 September 2014.

7. Mohan S, Campbell N, Chockalingam A. Time to effectively address hypertension in India. Indian $\mathrm{J}$ Med Res. 2013;137(4):627-31.

8. James PA, Oparil S, Carter BL, Cushman WC, DennisonHimmelfarb C, Handler J, et al. Evidence-based guideline for the management of high blood pressure in adults. JAMA. 2013;1097(5):1-14.

9. Kale A, Maniyar YA. Prescribing patterns of antihypertensive drugs in a tertiary care hospital. Sch Acad J Pharm. 2013;2(5):416-8.

10. Pickering TG, Hall JE, Appel LJ, Falkner BE, Graves J, Hill MN, et al. Recommendations for blood pressure measurement in humans and experimental animals: part 
1: blood pressure measurement in humans. Circulation. 2005;111(5):697-716.

11. Biradar S, Reddy S, Raju S, Kapatae R. Assessment of pharmacist mediated patient counseling on knowledge, attitude and practices on hypertension in compliance with antihypertensive drugs in South Indian city. Int J Pharm Life Sci. 2013;4(3):2489-91.

12. Fowad K, Mohammad A, Mohammad A, Prem K, Krishna P. Antihypertensive Medication Prescribing Pattern in a University Teaching Hospital in South Delhi. Int J Pharm Sci Res. 2012;3(7):2057-63.

13. Bajaj JK, Sood M, Singh SJ, Jerath P. Prescription Patterns of antihypertensive drugs and adherence to JNC VII guidelines in a tertiary care hospital in North India. Int J Med Clin Res. 2012;3(2):118-20.

14. Solanki K, Mistry R, Singh A, Patel N, Jadav S. Drug utilization study of anti-hypertensive drugs and their adverse effects in patients attending Medicine Opd of a tertiary care hospital. J Clin Exp Res. 2013;1(3):1.

15. Almas A, Ehtamam A, Khan AH. Spectrum of antihypertensive therapy in South Asians at a tertiary care hospital in Pakistan. BMC Res Notes. 2011 Dec;4(1):318.

16. Nwaka AL, Nduka SO, Osonwa UE, Maureen A, Samuel UE, Ele GN. Evaluation of the prescription pattern of antihypertensive agents in a tertiary health institution in Nigeria. African $\mathrm{J}$ Pharm Pharmacol Full. 2015;9(10):321-6.

17. Rajasekhar DG, Prasanna DG, Chandrakanth P. Prescribing pattern of antihypertensive drugs based on compelling indications with hypertension. Int J Pharm Pharm Sci. 2016;8(2):72-5.

18. Zachariah G, Harikrishnan S, Krishnan MN, Mohanan PP, Sanjay G, Venugopal K, et al. Prevalence of coronary artery disease and coronary risk factors in Kerala, South India: A population survey - Design and methods. Indian Heart J. Elsevier Ltd. 2013;65(3):243-9.

19. Torvi JR, Narendra SH. Prescription Pattern of Antihypertensive Drugs in a Tertiary Hospital. J Pharm Biomed Sci. 2011;9(9).

20. Tandon V, Sharma S, Mahajan S, Mahajan A, Khajuria $\mathrm{V}$, Mahajan V, et al. Antihypertensive drug prescription patterns, rationality, and adherence to Joint National Committee-7 hypertension treatment guidelines among Indian postmenopausal women. J Midlife Health. 2014;5(2):78

21. Konwar M, Paul PK, Das S. Prescribing pattern of antihypertensive drugs in essential hypertension in medicine out patients department in a tertiary care hospital. Asian J Pharm Clin Res. 2014;7(Suppl. 2):1424.

22. Rachana PR, Anuradha HV. Anti hypertensive prescribing patterns and cost analysis for primary hypertension: a retrospective study. J Clin Diagnostic. 2014;8(9):19-22.
23. Joseph S, Varghese N, Thomas L. A study on prescribing pattern of anti hypertensive medications in a tertiary care hospital in Malabar region. Der Pharm Lett. 2014;6(4):132-7.

24. Mancia G, Fagard R, Narkiewicz K, Redon J, Zanchetti A, Bohm M, et al. 2013 ESH / ESC Guidelines for the management of arterial hypertension The Task Force for the management of arterial hypertension of the European Society of Hypertension (ESH) and of the European Society. Eur Hear J. 2013;34:2159-219.

25. Johnson ML, Singh H. Patterns of antihypertensive therapy among patients with diabetes. J Gen Intern Med. 2005;20(9):842-6.

26. Vurumadla S, Rakshith V, Ch M, Venkateshwarlu K. A study on symptoms, risk factors and prescribing pattern of drugs used in stroke patients. Int J Pharm Pharm Sci. 2015;7(1):12-7.

27. Preethi Prathyusha B, Abdul Naveed, Shreya S SLG and VR. Prescribing pattern of drugs in stroke patients admitted to a multi specialty hospital, India. Indo Am J Pharm Res. 2014;4(2):1015-20.

28. Brunton LL, Chabner BA, Knollmann BC. Goodman and Gillman. 12th ed. San Diego, California; 2010.

29. Baskota M, Rao BS, Shakaya R. Study on the prescribing patterns of drugs used in heart failure. Kathmandu Univ J Sci Eng Technol. 2006;2(1):1-10.

30. Gradman AH, Basile JN, Carter BL, Bakris GL. Combination therapy in hypertension. $\mathrm{J}$ Am Soc Hypertens. Elsevier Ltd; 2010;4(1):42-50.

31. WHO. Introduction to Drug Utilization Research Introduction to Drug Utilization Research. 2003:1-49. Available http://apps.who.int/medicinedocs/en/d/Js4876e/. Accessed 1 January 2016.

32. Shalini S, Ravichandran V, Bk M, Sk D, Saraswathi R. Drug utilization studies - an overview. Int J Pharm Sci Nanotechnol. 2010;3(1):803-10.

33. Rimoy GH, Justin-Temu M, Nilay C. Prescribing Patterns and Cost of Antihypertensive Drugs in Private Hospitals in Dar es Salaam, Tanzania. East Cent African J Pharm Sci. 2008;11:69-73.

34. CDSCO. National List of Essential Medicines- 2015. 2015:1-117. Available at: http://cdsco.nic.in/WriteReadData/NLEM-2015/NLEM, 2015.pdf. Accessed 1 January 2016.

Cite this article as: Ramadas $S$, Sujatha MB, Andrews MA, Sanalkumar K. B. Drug utilization study of antihypertensive drugs and prevalence of blood pressure control in adult hypertensive patients based on JNC VIII guidelines in a tertiary care hospital: a cross sectional study. Int J Basic Clin Pharmacol 2019;8:245-52. 